\title{
Heat Transfer in Air Flow Past a Bottom Channel Wall- Attached Diamond-Shaped Baffle - Using a CFD Technique
}

\author{
Younes Menni1 ${ }^{1 *}$, Ali J. Chamkha²,3, Chafika Zidani', Boumédiène Benyoucef ${ }^{1}$ \\ 1 Unit of Research on Materials and Renewable Energies, Department of Physics, Faculty of Sciences, \\ Abou Bekr Belkaid University, BP 119-13000-Tlemcen, Algeria \\ 2 Mechanical Engineering Department, Prince Sultan Endowment for Energy and Environment, \\ Prince Mohammad Bin Fahd University, Al-Khobar 31952, Saudi Arabia \\ ${ }^{3}$ RAK Research and Innovation Center, American University of Ras Al Khaimah, P.O.B. 31208, Al Jazeera Al Hamra, Ras Al Khaima \\ United Arab Emirates \\ * Corresponding author, e-mail: menniyounes.cfd@gmail.com
}

Received: 05 May 2018, Accepted: 08 January 2019, Published online: 25 March 2019

\begin{abstract}
A computational analysis has been conducted to investigate turbulent flow and convective thermal transfer characteristics in a twodimensional horizontal rectangular section channel with a hot lower wall-mounted diamond-shaped baffle. The calculations are based on the finite volume method, by means of Commercial Computational Fluid Dynamics software FLUENT, standard k-epsilon turbulence model with QUICK numerical scheme, and the SIMPLE discretization algorithm has been applied. The fluid flow and heat transfer characteristics, i.e., dynamic pressure coefficient, stream function, mean, axial, and transverse velocities, turbulent viscosity, temperature field, skin friction coefficients, local and average Nusselt numbers, and thermal enhancement factor are presented for flow Reynolds numbers based on the aeraulic diameter of the computational domain ranging from 12,000 to 32,000 at constant surface temperature condition along the upper and lower walls. Effect of the diamond configuration of the insulated baffle is studied numerically and the data obtained from this same baffle model are also compared with that of the simple flat rectangular baffle under similar operating conditions. Over the range under investigation, the improvements are found to be around 3.962 and 29.820 times higher than the smooth air channel with no baffle for heat thermal transfer and skin friction factor, respectively. The maximum TEF is around 1.292 at the highest Reynolds number value, $\mathrm{Re}=32,000$.
\end{abstract}

Keywords

airflow, CFD, diamond baffle, rectangular channel, turbulence

\section{Introduction}

Convective heat transfer from surfaces has been the topic of several studies in recent year. This interest in the subject stems from various engineering applications in geothermal reservoirs, petroleum industries, transpiration cooling, storage of nuclear waste materials, separation processes in chemical industries, building thermal insulation, and solar heating systems. There are many excellent numerical and experimental studies for convective heat transfer of fluids in channels.

Kelkar and Patankar [1] presented a numerical analysis for the flow and heat transfer in a parallel plate channel with staggered fins. The passage was formed by two parallel plates to which fins were attached in a staggered fashion. Both the plates were maintained at a constant temperature.
Streamwise periodic variation of the cross-sectional area causes the flow and temperature fields to repeat periodically after a certain developing length. Computations were performed for different values of the Reynolds number, the Prandtl number, geometric parameters, and the fin-conductance parameter. The fins were found to cause the flow to deflect significantly and impinge upon the opposite wall so as to increase the heat transfer significantly. However, the associated increase in pressure drop was an order of magnitude higher than the increase in heat transfer. Streamline patterns and local heat transfer results were presented in addition to the overall results.

Habib et al. [2] reported an experimental study to provide a detailed investigation of the turbulent flow and the 
heat transfer in a rectangular duct with segmented baffles at a uniform wall heat flux condition along the top and bottom walls. The experimental runs were carried out for different values of Reynolds number and baffle-height ratios. The flow is characterized by a large recirculation zone formed behind the obstructions and by regions of large velocity gradients. The results indicated that the heat transfer parameters increase with the increase of Reynolds number and baffle-height ratio. However, the increase in the pressure loss coefficient was much higher than the increase in heat transfer coefficient. The results indicated that for fluids of low heat transfer coefficient, such as gases, only marginal heat transfer augmentation may be expected.

Hwang et al. [3] numerically investigated the turbulent flow past a surface-mounted two-dimensional rib with varying lengths. Computations for flow over a surface-mounted rectangular rib were conducted for the variations in the rib lengths. Results indicated that upstream of the obstacle, the length of the recirculating region remains unchanged with varying rib lengths; while the downstream length of the recirculating region is a strong function of rib length and changes nearly linearly for the varying lengths of $B / H=0.1$ to $B / H=4.0$. Reattachment on top of the rib, owing to its increasing length, affected the downstream boundary layer development.

Karwa et al. [4] presented the paper results of an experimental study of heat transfer and friction in rectangular ducts with baffles (solid or perforated) attached to one of the broad walls. The duct has width-to-height ratio of 7.77 ; the baffle pitch-to-height ratio is 29; the baffle height-toduct height ratio is 0.495 . The Reynolds number of the study ranges from 2850 to 11500 . The baffled wall of the duct was uniformly heated while the remaining three walls were insulated. These boundary conditions correspond closely to those found in solar air heaters. They showed an enhancement of $73.7-82.7 \%$ in the Nusselt number over a smooth duct for the solid baffles and from $60.6-62.9 \%$ to $45.0-49.7 \%$ for the perforated baffles (the enhancement decreases with the increase in the open area ratio). The friction factor for the solid baffles was found to be 9.6 - 11.1 times of the smooth duct, which decreased significantly for the perforated baffles with the increase in the open area ratio; it is only $2.3-3.0$ times for the baffles with an open area ratio of $46.8 \%$. The baffles with the highest open area ratio give the best performance compared to a smooth duct at equal pumping power.

Singh et al. [5] conducted experiments on rectangular duct having one broad wall roughened with discrete V-down rib and subjected to constant heat flux. The effect of roughness parameters on Nusselt number and friction factor was determined and the results obtained were compared with those of smooth duct. The maximum increase in $\mathrm{Nu}$ and $f$ over that of smooth duct was 3.04 and 3.11 folds respectively. The rib parameters corresponding to maximum increase in $\mathrm{Nu}$ and $f$ were $d / w=0.65, g / e=1.0$, $P / e=8.0, \alpha=60^{\circ}$ and $e / D_{h}=0.043$. Correlations for the $\mathrm{Nu}$ and $f$ in terms of Re and rib parameters were developed.

Tamna et al. [6] presented a study on heat transfer augmentation in a solar air heater channel fitted with multiple V-baffle vortex generators (BVG). During the test air was passed through the test channel under a uniform wall heatflux of the absorber plate. The fluid flow and heat transfer characteristics were presented for Reynolds numbers based on the channel hydraulic diameter ranging from 4000 to 21,000. The V-baffles were applied at a relative baffle height (in terms of blockage ratio, $B R=b / H=0.25$ ) and attack angle of $45^{\circ}$ with respect to the main flow direction. The use of BVG in the channel was to generate multiple longitudinal vortex flows through the test channel to increase turbulence intensity and stronger mixing of fluid between the core and the near-wall flow. Influences of three different baffle pitch to channel-height ratios $(P R=P / H=0.5$, 1 and 2) on heat transfer and pressure drop in terms of respective Nusselt number and friction factor (or energy loss for propelling air through the channel) were examined.

Wen et al. [7] proposed an improved structure of ladder-type fold baffle to block the triangular leakage zones in original heat exchangers with helical baffles. The numerical results showed that the distribution of shell side velocity and temperature in improved heat exchanger are more uniform and axial short circuit flow is eliminated. The experimental results showed that the shell-side heat transfer coefficient $\alpha_{0}$ and overall heat transfer coefficient $K$ are improved by $22.3-32.6 \%$ and $18.1-22.5 \%$, respectively. The increment in shall-side pressure drop was about $0.911-9.084 \mathrm{kPa}$, while the corresponding pumping power penalty was about $2-80 \mathrm{~W}$. The thermal performance factor TEF enhanced by $18.6-23.2 \%$, which demonstrates that the ladder-type fold baffles can effectively improve the heat transfer performance of heat exchangers with helical baffles. The results of this paper are of great significance in the optimal design of the heat exchanger.

Zhao et al. [8] experimentally studied the pressure drop and friction factor of de-ionized water flowing across staggered mini pin fins of the same height and transverse spacing but with different pin density and different shapes of circular, elliptical, square, diamond and triangle, in a 
rectangular channel. Comparisons were made between experimental data and existing correlations, and results showed that there were large deviations between them.

$\mathrm{Du}$ et al. [9] designed a special flow layout with U-shaped tubes applied in the laboratory for testing the heat transfer performances (HTPs) of molten salt in the shell side of a shell-and-tube heat exchanger (STHE). Based on this design, the transitional convective HTPs $(6142<\operatorname{Re}<9125)$ of molten salt with higher temperature (209.41-241.49 ${ }^{\circ} \mathrm{C}$ ) in the STHE with segmental baffles (STHE-SBs) were experimentally studied, and the corresponding heat transfer correlations were fitted.

Skullong et al. [10] carried out an experimental and numerical work to study the heat transfer enhancement in a heat exchanger square-duct fitted with $30^{\circ}$ oblique horseshoe baffles (HB). Numerical flow and heat transfer behaviors such as streamlines, temperature and Nusselt number contours of the duct flow model were also reported.

Mellal et al. [11] investigated a three-dimensional numerical simulation of turbulent fluid flow and heat transfer in the shell side of a shell and tube heat exchanger (STHE). The investigations were performed with the CFD COMSOL Multiphysics 5.1 software using the finite elements method, for Reynolds number ranging from 3000 to 10000 .

Mokhtari et al. [12] numerically characterized and studied the mixed convection of a three-dimensional square duct with various arrangements of fins in both laminar and turbulent flow. The computations confirmed that fin arrangement significantly changes the temperature distribution and cooling performance of the fins.

Amraoui and Aliane [13] presented the study of fluid flow and heat transfer in solar flat plate collector by using Computational Fluid Dynamics (CFD) which reduces time and cost. In those studies, the computational fluid dynamics (CFD) tool was used to simulate the solar collector for better understanding the heat transfer capability.

Rashidi et al. [14] performed a review of the literature on the area of heat transfer improvement employing a combination of nanofluid and inserts. Inserts are baffles, twisted tape, vortex generators, and wire coil inserts. The progress made and the current challenges for each combined system are discussed, and some conclusions and suggestions are made for future research.

Selimefendigil et al. [15] numerically investigated the fluid flow and heat transfer in a vertical lid-driven $\mathrm{CuO}$-water nanofluid-filled square cavity with a flexible fin attached to its upper wall under the influence of an inclined magnetic field. The influence of Richardson number (between 0.01 and 100), Hartmann number (between 0 and 50), inclination angle of the magnetic field (between 0 and $90 \%$ ), nanoparticle volume fraction (between 0 and 0.05 ) and Young's modulus of flexible fin (between 250 and 5000) on the flow and heat transfer were numerically studied. They observed that the presence of the elastic fin affects the flow field and thermal characteristics of the cavity.

Akbarzadeh et al. [16] investigated the combined effects of using nanofluid, a porous insert and corrugated walls on heat transfer, pressure drop and entropy generation inside a heat exchanger duct. A series of numerical simulations were conducted for a number of pertinent parameters. They showed that the waviness of the wall destructively affects the heat transfer process at low wave amplitudes and that it can improve heat convection only after exceeding a certain amplitude. A number of design recommendations were made on the basis of the findings of this study.

Heydari et al. [17] numerically studied the effect of attack angle of triangular ribs, by using finite-volume method, in a two-dimensional microchannel. In this study, the effects of variations in attack angles on triangular ribs, volume fraction of nanoparticles, nanoparticles diameter and Reynolds number were investigated. Using triangular rib with higher attack angle can improve heat transfer significantly due to the high-velocity gradients and better mixing of fluid flow.

Khoshvaght-Aliabadi et al. [18] used the delta-winglets to enhance heat transfer in wavy plate-fins (WPFs) in presence of $\mathrm{Al}_{2} \mathrm{O}_{3} /$ water nanofluid. Impacts of the most effective parameters, including waviness aspect ratio $(c=0.33,0.42$, and 0.51$)$, winglets height $(h=2,4$, and $6 \mathrm{~mm})$, nanoparticles mass fraction (0-0.4\%), and Reynolds number (450011,500), were examined. The results showed that the use of proposed geometries leads to a considerable heat transfer enhancement in plate-fin heat exchangers, especially at the highest values of waviness aspect ratio and winglets height. The maximum heat transfer enhancement of $11.3 \%$ is observed for $0.4 \%$ nanofluid flow over the WPF with $c=0.51$ and $h=6 \mathrm{~mm}$. Other works can be found in the literature, i.e, Menni and Azzi [19], Menni et al. [20-23], Fodor [24], Rábai and Vad [25], Hegedüs et al. [26], Füle and Hernádi [27], Goda and Bánhidi [28], Bidar et al. [29], Fenyvesi and Horváth [30], and Noghrehabadi et al. [31-33].

The manuscript reports a numerical study on turbulent forced-convection flow and friction loss characteristics in a solar air channel of rectangular section. A two-dimensional diamond-shaped baffle was inserted in the field to force a recirculation to improve the thermal transfer rate. In particular, the fields of dynamic pressure, stream 
function, velocity, turbulent viscosity, and temperature, the dimensionless profiles of axial velocity, the local and average numbers of Nusselt, the coefficient and factor of skin friction, and the thermal performance factor are obtained. The Reynolds number is ranged from 12,000 to 32,000 . The finite volume method is adopted for modelling the problem by using the software Fluent.

\section{Mathematical modelling}

Fig. 1 shows schematically the computational domain with the diamond baffle and boundary conditions for this investigation. The flow is assumed to be turbulent and fluid properties to be constant. Air, whose Prandtl number (Pr) is 0.71 , is the working fluid used, and the Reynolds numbers considered range from 12,000 to 32,000 . A uniform one-dimensional velocity $\left(U_{i n}\right)$ is applied as the aeraulic boundary condition at the intake of channel, as presented in more details in Demartini et al. [34] and Nasiruddin and Kamran Siddiqui [35]. A constant surface temperature condition of $375 \mathrm{~K}$ was applied on the upper and lower walls of the channel as the thermal boundary condition [35]. The temperature of the working fluid was set equal to $300 \mathrm{~K}$ at the inlet of the channel [35]. In addition, non-slip and impermeability boundary conditions are imposed at the walls [34], and in the channel outlet it is prescribed the atmospheric pressure [34]. Structural parameters were based on the experimental study of Demartini et al. [34]. Finally, a conventional flat rectangular baffle under similar operating conditions is inserted into the filed for comparison.

The channel model with one diamond-shaped baffle under examination is governed by the steady two-dimensional form of continuity, the Reynolds-Averaged NavierStokes, and energy equations.

In the Cartesian tensor system these equations can be written as follows:

Continuity equation:

$$
\frac{\partial u_{j}}{\partial x_{j}}=0
$$

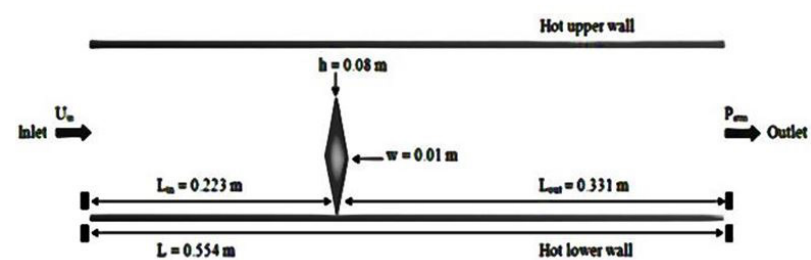

Fig. 1 Geometry under investigation.
Momentum equation:

$\rho u_{j} \frac{\partial u_{i}}{\partial x_{j}}=-\frac{\partial P}{\partial x_{i}}+\frac{\partial}{\partial x_{j}}\left(\mu \frac{\partial u_{i}}{\partial x_{j}}-\rho\right) \overline{u_{i}^{\prime} u_{j}^{\prime}}$

where $\rho$ is the fluid density, $P$ is the pressure, $\mu$ is the dynamic viscosity, $u_{i}$ and $u_{j}$ are mean velocity components in $x_{i}$ and $x_{j}$ directions, $u_{i}^{\prime}$ and $u_{j}^{\prime}$ are fluctuation velocity components in $x_{i}$ and $x_{j}$ directions.

Energy equation:

$\rho u_{j} \frac{\partial T}{\partial x_{j}}=\frac{\partial}{\rho x_{j}}\left(\left(\Gamma+\Gamma_{t}\right) \frac{\partial T}{\partial x_{j}}\right)$

where $\Gamma$ and $\Gamma_{t}$ are molecular thermal diffusivity and turbulent thermal diffusivity, respectively and are given by

$\Gamma=\mu / \operatorname{Pr}$ and $\Gamma_{t}=\mu_{t} / \operatorname{Pr}_{t}$.

Where

$-\rho \overline{u_{i}^{\prime} u_{j}^{\prime}}=\mu_{t}\left(\frac{\partial u_{i}}{\partial x_{j}}+\frac{\partial u_{j}}{\partial x_{i}}\right)-\frac{2}{3} \rho \delta_{i j} k$.

Where $\mu_{t}$ is the turbulent viscosity, $\delta_{i j}$ the Kroenecker delta, and $k$ the kinetic energy of the turbulence, defined as

$k=\frac{1}{2} \overline{u_{i}^{\prime} u_{j}^{\prime}}$.

The turbulent viscosity is defined as

$\mu_{t}=\rho C_{\mu} \frac{k^{2}}{\varepsilon}$.

The steady state transport equations of $k$ and $\varepsilon$ for $k$-epsilon turbulence model are expressed as, respectively,

$\frac{\partial}{\partial x_{j}}\left(\rho k u_{j}\right)=\frac{\partial}{\partial x_{j}}\left[\left(\mu+\frac{\mu_{t}}{\sigma_{k}}\right) \frac{\partial k}{\partial x_{j}}\right]+G_{k}+\rho \varepsilon$

$\frac{\partial}{\partial x_{j}}\left(\rho \varepsilon u_{j}\right)=\frac{\partial}{\partial x_{j}}\left[\left(\mu+\frac{\mu_{t}}{\sigma_{\varepsilon}}\right) \frac{\partial \varepsilon}{\partial x_{j}}\right]+C_{1 \varepsilon} \frac{\varepsilon}{k}-C_{2 \varepsilon} \rho \frac{\varepsilon^{2}}{k}$.

Where

$C_{\mu}=0.99, C_{1 \varepsilon}=1.44, C_{2 \varepsilon}=1.92, \sigma_{k}=1.0, \sigma_{\varepsilon}=1.3$

are chosen to be empirical constants [36] in the turbulence transport equations. $G_{k}$ is the production rate of the kinetic energy due to the energy transfer from the mean flow to turbulence, defined as

$G_{k}=-\rho \overline{u_{i}^{\prime} u_{i}^{\prime}} \frac{\partial u_{j}}{\partial x_{i}}$. 
The production term $G_{k}$ is modeled according to Boussinesq's hypothesis, by

$$
G_{k}=\mu_{t} S^{2} \text {. }
$$

Where $S$ is the modulus of the mean strain tensor, given by

$$
S=\sqrt{2 S_{i j} S_{i j}}
$$

and the strain tensor is

$$
S_{i j}=\frac{1}{2}\left(\frac{\partial u_{i}}{\partial x_{i}}+\frac{\partial u_{j}}{\partial x_{i}}\right)
$$

which is the symmetrical part of the velocity gradient. The Law-of-the wall for mean velocity yields is defined as

$u^{*}=\frac{1}{\kappa} \ln \left(E y^{*}\right)$.

The value of $y^{*}$ is taken as the minimum distance of the first grid point $(p)$ from the adjacent wall, given by

$$
y^{*}=\frac{\rho C_{\mu}^{1 / 4} k_{p}^{1 / 2} y_{p}}{\mu} \text {. }
$$

Where $\kappa$ is the Von Kármán constant, $E$ is an empirical constant, $k_{p}$ represents the kinetic energy of turbulence at position $p, y_{p}$ is the distance from position $p$ to the wall. The boundary condition for $k$ imposed at the wall is

$\frac{\partial k}{\partial n}=0$.

Where $n$ is the local coordinate normal to the wall. The production rate of $k$ and the averaged dissipation rates over the near-wall cell for the $k$-equation as well as the value of $\varepsilon$ at the point $p$ are computed respectively from following equations:

$$
\begin{aligned}
& G_{k}=\tau_{w} \frac{u_{p}}{y_{p}} \\
& \bar{\varepsilon}=\frac{C_{\mu}^{3 / 4} k_{p}^{3 / 2}}{\kappa y_{p}} \ln \left(E y^{*}\right) \\
& \varepsilon=\frac{C_{\mu}^{3 / 4} k_{p}^{3 / 2}}{\kappa y_{p}} .
\end{aligned}
$$

Where $u_{p}$ is the mean velocity of the fluid at position $p$, and $\tau_{w}$ the wall shear stress defined as

$$
\tau_{w}=\frac{\rho u_{p} C_{\mu}^{1 / 4} k_{p}^{1 / 2} \kappa}{\ln \left(E y^{*}\right)} .
$$

For the temperature boundary condition, the heated flux to the channel wall is derived from the thermal wall function:

$$
q_{w}=\frac{\left(T_{w}-T_{p}\right) \rho C_{p} C_{\mu}^{1 / 4} k_{p}^{1 / 2}}{\operatorname{Pr}_{t}\left(\frac{\ln \left(E y^{*}\right)}{\kappa+P}\right)} \text {. }
$$

Where the empirical function $P$ is specified as

$$
P=\frac{\pi / 4}{\sin (\pi / 4)}\left(\frac{A}{\kappa}\right)^{1 / 2}\left(\frac{\operatorname{Pr}}{\operatorname{Pr}_{t}}-1\right)\left(\frac{\operatorname{Pr}_{t}}{\operatorname{Pr}}\right)^{1 / 4}
$$

and $C_{p}$ is the specific heat of fluid, $q_{w}$ represents the wall heat flux, $T_{p}$ is the temperature at the cell adjacent to the wall, $T_{w}$ is the temperature at the wall, $\mathrm{Pr}$ is the molecular Prandtl number, $\operatorname{Pr}_{t}$ is the turbulent Prandtl number, and $A$ is the Van Driest constant.

The thermal aerodynamic boundary conditions for the current problem is defined as at the intake, $x=0$ :

$u=U_{\text {in }}$

$v=0$

$k_{\text {in }}=0.005 U_{\text {in }}^{2}$

$\varepsilon_{i n}=0.1 k_{i n}^{2}$

$T=T_{i n}$

at the outlet, $x=L$ :

$P=P_{a t m}$

$\partial \phi / \partial x=0$

in which $\phi$ is a variable used to represent quantities such as velocity components $u$ and $v$, temperature $T$, turbulent kinetic energy $k$ or turbulent energy dissipation rate $\varepsilon$.

At the walls, $y=H / 2$ and $y=-H / 2$ :

$$
\begin{aligned}
& u=v=0 \\
& k=\varepsilon=0 \\
& T=T_{w} .
\end{aligned}
$$

At the interface fluid / solid:

$\lambda_{f} \frac{\partial T_{f}}{\partial n}=\lambda_{s} \frac{\partial T_{s}}{\partial n}$

$T_{f}=T_{s}$. 
Where $\lambda_{f}$ and $\lambda_{s}$ are thermal conductivities of fluid and solid, respectively. The Reynolds number is defined as follows:

The flow Reynolds number, Re is calculated as

$\operatorname{Re}=\rho \bar{U} D_{h} / \mu$.

The hydraulic diameter of the channel, $D_{h}$ is calculated as

$D_{h}=2 H W /(H+W)$.

The skin friction coefficient, $C f$ is given by

$C_{f}=2 \tau_{w} / \rho \bar{U}^{2}$.

The friction factor, $f$ is computed as

$f=2(\Delta P / L) D_{h} / \rho \bar{U}^{2}$.

The local Nusselt number, $\mathrm{Nu}_{x}$ which can be written as

$\mathrm{Nu}_{x}=h_{x} D_{h} / k_{f}$.

The average Nusselt number, $\mathrm{Nu}$ can be obtained by

$\mathrm{Nu}=\frac{1}{L} \int \mathrm{Nu}_{x} \partial x$.

The following expression represents the thermal enhancement factor, TEF:

$T E F=\left(\mathrm{Nu} / \mathrm{Nu}_{0}\right) /\left(f / f_{0}\right)^{1 / 3}$.

The Dittus-Boelter and Petukhov correlations can be used to normalize the average Nusselt number and friction factor, respectively. The quantities $\mathrm{Nu}_{0}$ and $f_{0}$ are the average Nusselt number and the friction factor of the smooth channel, respectively. The Dittus and Boelter correlation [37] has the form:

$\mathrm{Nu}_{0}=0.023 \operatorname{Re}^{0.8} \operatorname{Pr}^{0.4}$ for $\operatorname{Re} \geq 10^{4}$.

The Petukhov correlation [38] has the form:

$f_{0}=(0.79 \ln \operatorname{Re}-1.64)^{-2}$ for $3 \times 10^{3} \leq \operatorname{Re} \leq 5 \times 10^{6}$.

\section{Numerical modelling}

The governing equations, i.e., continuity, momentum and energy equations, employed to simulate the incompressible steady fluid flow and heat transfer in the given computational domain are solved numerically using the finite volume method. Most of the details of the method can be found in [39]. A two-dimensional, non-uniform, structured, quadrilateral-type grid with refinement near of all solid boundaries in the two directions $X$ and $Y$ is used, as shown in Fig. 2. To ensure the accuracy and validity of the numerical model, different mesh cells are examined and a mesh system of $245 \times 95$ cells in $X$ and $Y$ directions respectively, is chosen in view of saving solution precision.

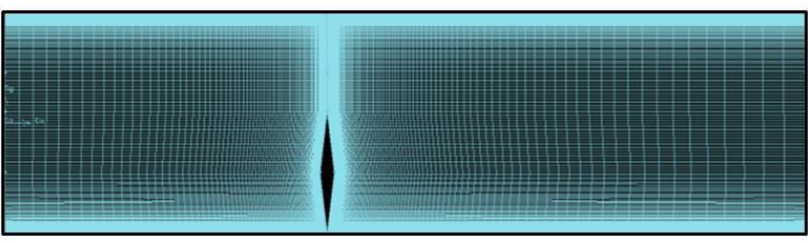

Fig. 2 Grid system.

The heat transfer $(\mathrm{Nu})$ and friction factor $(f)$ verification of the present smooth rectangular air channel with no obstacle as baffle or fin is conducted by comparing with the previous data under a similar operating condition as reported in Figs. 3 and 4, respectively.

The current CFD smooth rectangular air channel data is found to be in good agreement with exact solution data obtained from the Dittus-Boelter and Petukhov correlations for both the $\mathrm{Nu}$ and the $f$, respectively.

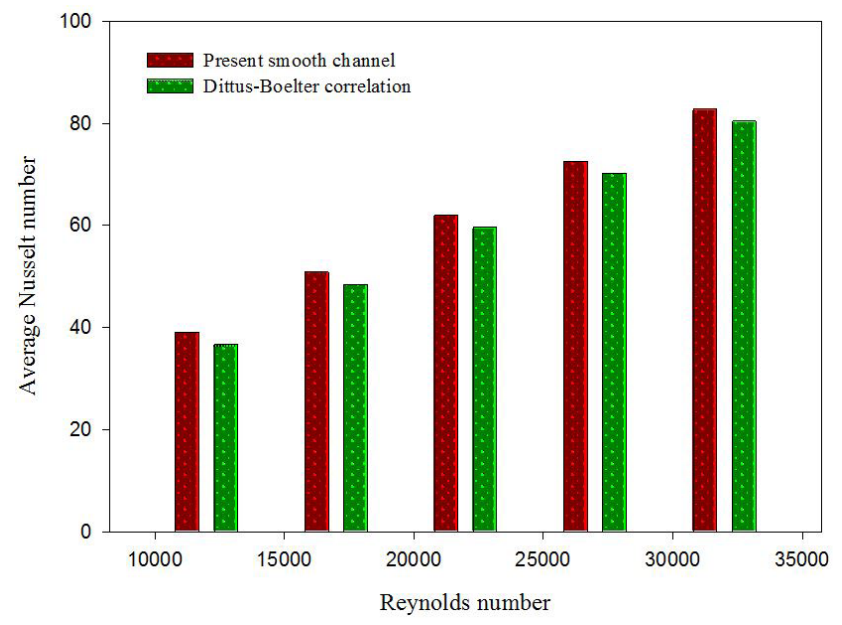

Fig. 3 Verification of Nusselt number for smooth air channel with no baffle.

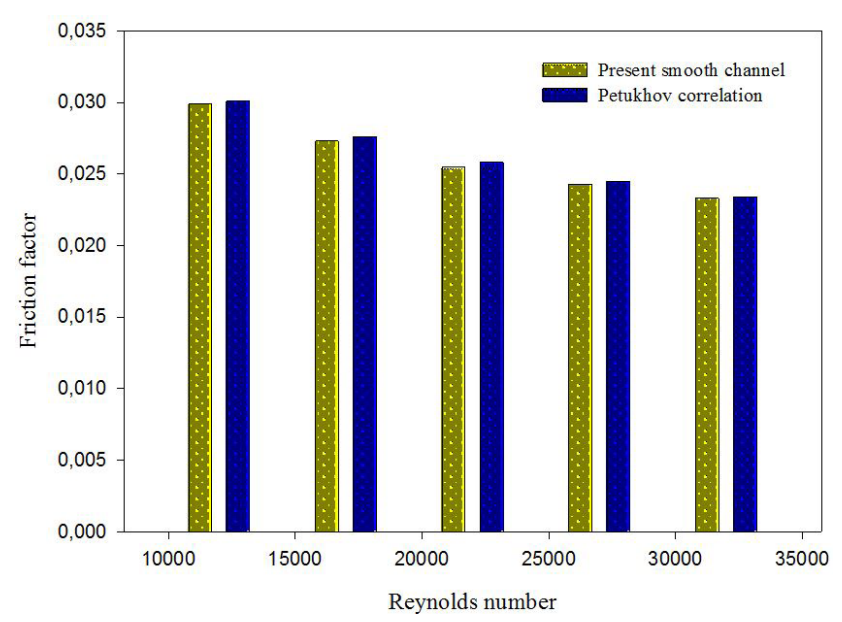

Fig. 4 Verification of friction factor for smooth air channel with no baffle. 


\section{Results and Discussion}

\subsection{Stream function}

Fig. 5 (a)-(e) shows the contour plots of streamlines for the cases of $\mathrm{Re}=12,000,17,000,22,000,27,000$ and 32,000, respectively. The plots reveal the existence of three main regions. In the first region, just upstream of the diamond-shaped baffle, the fluid is accelerated and arrives with an axial speed. At the approach of this same baffle, the current lines are deflected. In the second region, located between the top of diamond baffle and the upper wall of the channel, the flow is accelerated due to the effect of cross-sectional reduction. In the third region, downstream of the diamond, the current lines are generated by the effect of flow expansion, thus leaving the section formed by the baffle and the top channel wall. The most important phenomenon occurring in this zone is the formation of a recirculating flow whose extent is proportional to the Reynolds number.

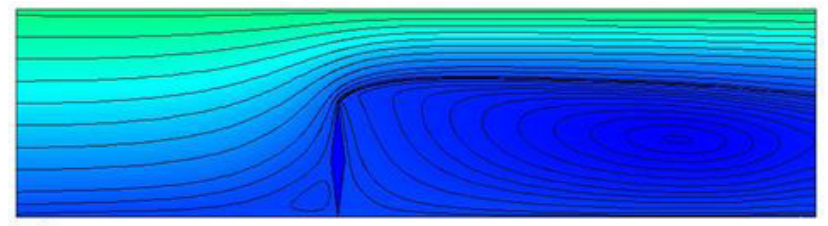

(a)

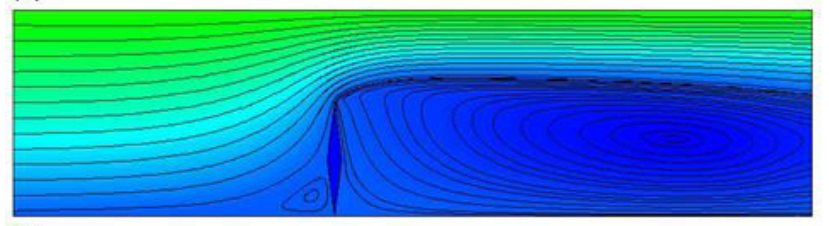

(b)

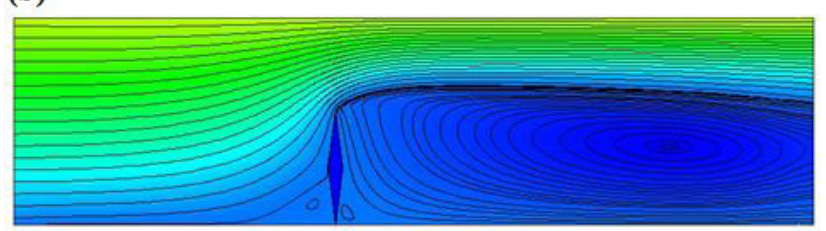

(c)

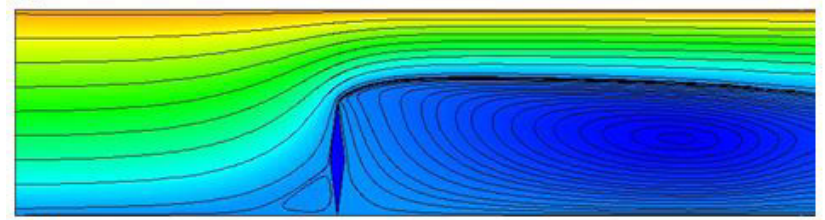

(d)

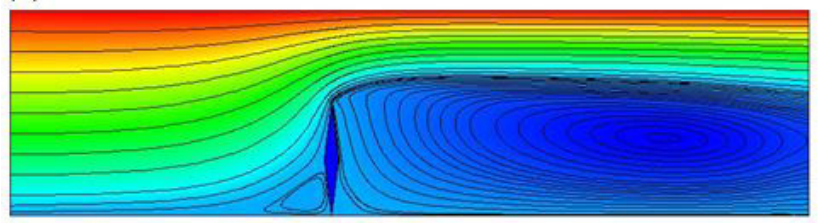

(e)

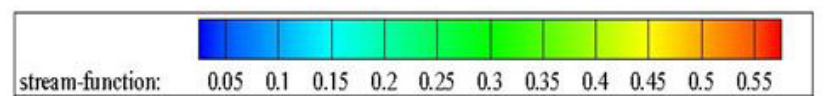

Fig. 5 Variation of streamlines with Reynolds number: (a) $\operatorname{Re}=12,000$, (b) $\operatorname{Re}=17,000$, (c) $\operatorname{Re}=22,000$, (d) $\operatorname{Re}=27,000$, and (e) $\operatorname{Re}=32,000$.

\subsection{Velocity-magnitude}

The mean velocity fields in the whole domain examined are presented in Fig. 6 (a)-(e) for cases $\mathrm{Re}=12,000,17,000$, $22,000,27,000$, and 32,000 , respectively. It can clearly be noticed that the values of the fluid velocity are very low in the vicinity of the diamond baffle, especially in the downstream region; this is due to the presence of the recirculation zone. Far from this zone, the current lines become parallel, which results in the progressive development of the flow. One should also note that the mean velocity increases in the space between the end of diamond and the upper wall of the channel. This rise in mean velocity is generated first by the presence of the diamond baffle and then by the presence of a recycling which results in a sudden change in the direction of the flow. It is also observed that the highest values of the mean velocity appear near the top of the channel, with a process of acceleration that begins just after the diamond

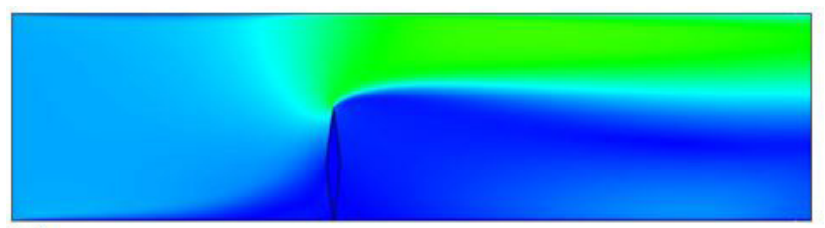

(a)

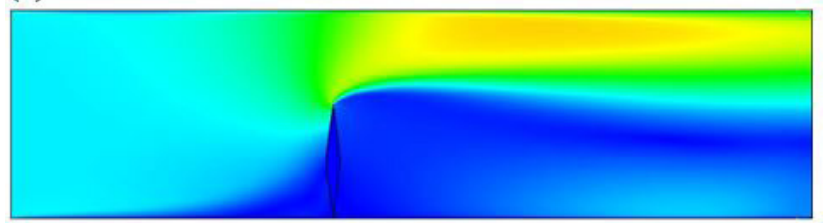

(b)

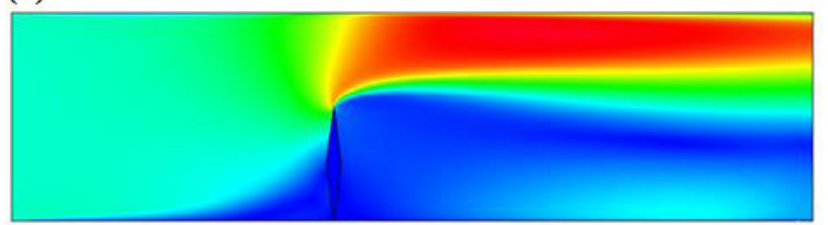

(c)

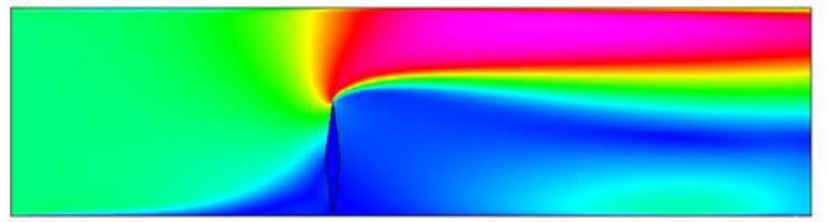

(d)

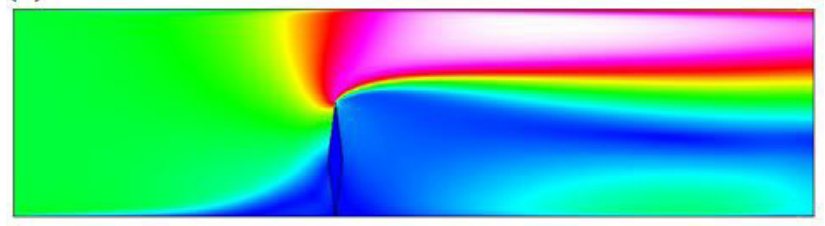

(d)

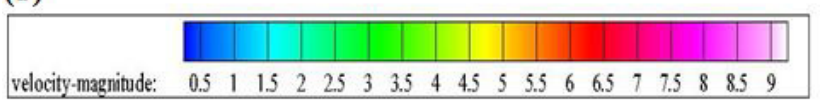

Fig. 6 Variation of mean velocity with Reynolds number:

(a) $\operatorname{Re}=12,000$, (b) $\operatorname{Re}=17,000$, (c) $\operatorname{Re}=22,000$, (d) $\operatorname{Re}=27,000$, and (e) $\operatorname{Re}=32,000$. 
baffle, thus approaching values of the order of $904.421 \%$ of the inlet velocity, at the highest value of Reynolds number, $\mathrm{Re}=32,000$. From Fig. 6, it can clearly be seen that the mean velocity is proportional to the Reynolds number, for the case of the configuration under study.

\subsection{Axial component of velocity}

Fig. 7 (a)-(e) presents the distribution of axial velocity fields for various values of the Reynolds number. Note that the presence of the diamond baffle in the lower half of the channel induces a strong decrease in the axial velocity. Negative axial velocities indicate the presence of a large recirculation zone located downstream of this same diamond, paradoxically in the upper half, where the

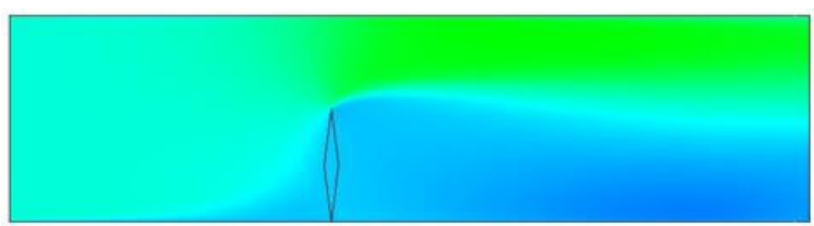

(a)

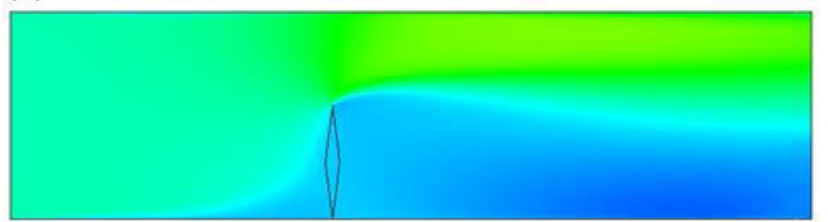

(b)

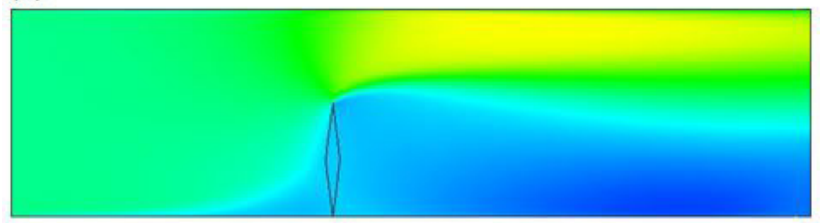

(c)

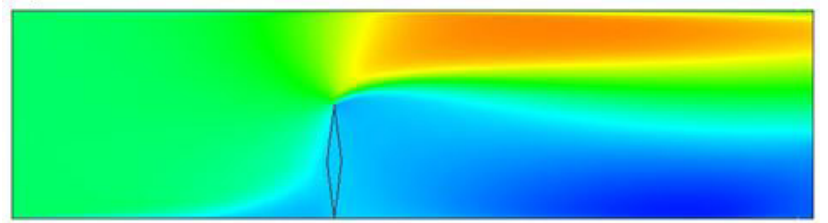

(d)

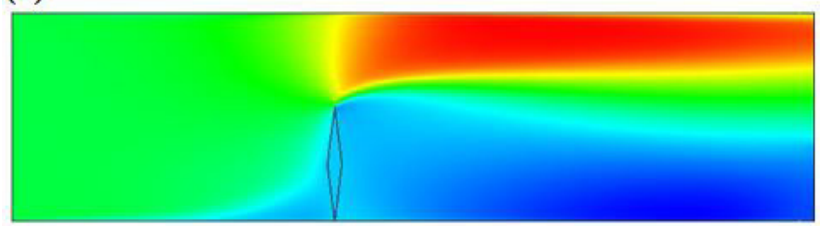

(e)

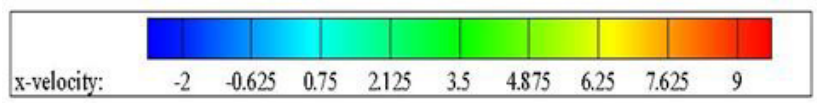

Fig. 7 Variation of axial velocity with Reynolds number:

(a) $\operatorname{Re}=12,000$, (b) $\operatorname{Re}=17,000$, (c) $\operatorname{Re}=22,000$, (d) $\operatorname{Re}=27,000$, and (e) $\operatorname{Re}=32,000$. flow increases, and particularly in the vicinity of the passage above the diamond. The increase in the Reynolds number leads to an acceleration of the flow and causes a rise in the axial speed.

\subsection{Transverse component of velocity}

Fig. 8 (a)-(e) shows the transverse component of the velocity versus the Reynolds number for the channel with a diamond baffle on the hot upper surface of the lower wall. From Fig. 8, it is interesting to note that for all the Reynolds number cases positive velocity gradients are observed at the top of the diamond geometry of the baffle. These same plots also indicate that the transverse component of the velocity increase considerably as the number of Reynolds number.

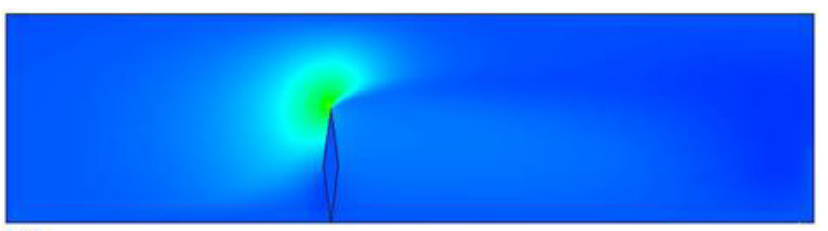

(a)

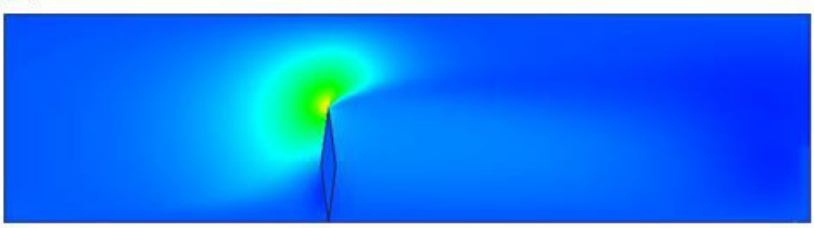

(b)

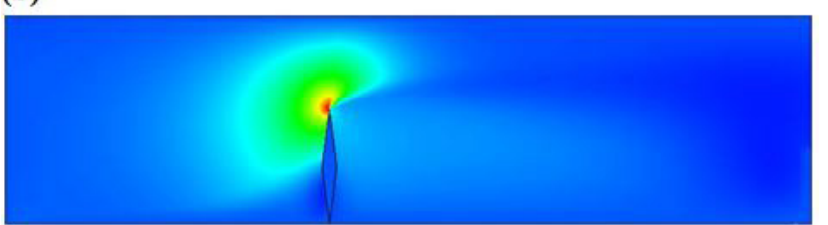

(c)

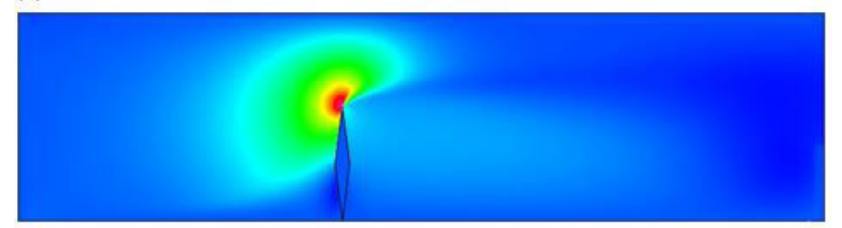

(d)

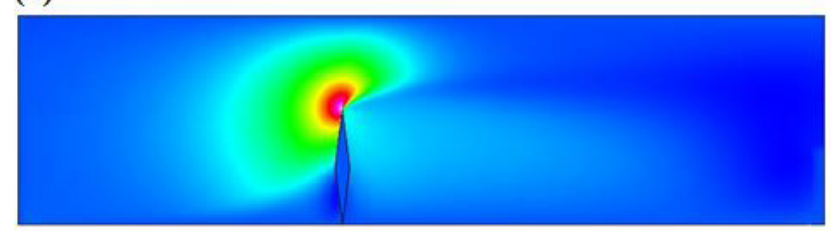

(e)

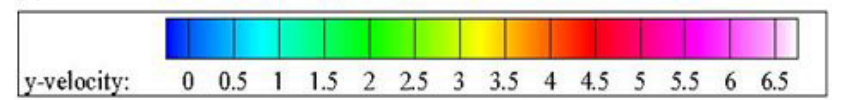

Fig. 8 Variation of transverse velocity with Re number:

(a) $\operatorname{Re}=12,000$, (b) $\operatorname{Re}=17,000$, (c) $\operatorname{Re}=22,000$, (d) $\operatorname{Re}=27,000$, and (e) $\operatorname{Re}=32,000$. 


\subsection{Turbulent kinetic energy}

The distribution of turbulent kinetic energy (TKE) fields along the airway and its variation as a function of Re number are presented in Fig. 9 (a)-(e). The TKE values range from negligible at small Reynolds numbers in different areas of the channel, to weak at intermediate Re numbers from the tip of the baffle to the exit, to considerable at the large values of Re.

\subsection{Turbulent intensity}

The effect of changing Reynolds number values on the flow structure in terms of turbulent intensity $(T I)$ for the channel with modern obstacle is represented in Fig. 10 (a)-(e). Through this figure (Fig. 10) and compared to the previous figure (Fig. 9), we note that the $T I$ values are increasing rapidly and widely with the rise in the Reynolds number compared to the $T K E$ of low acceleration.

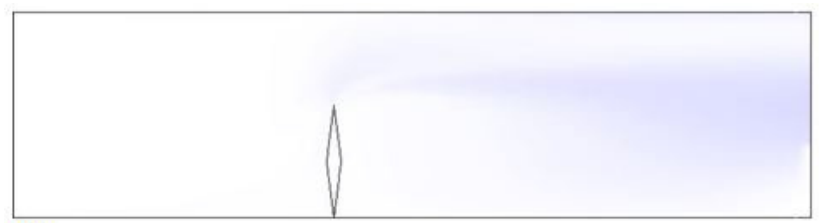

(a)

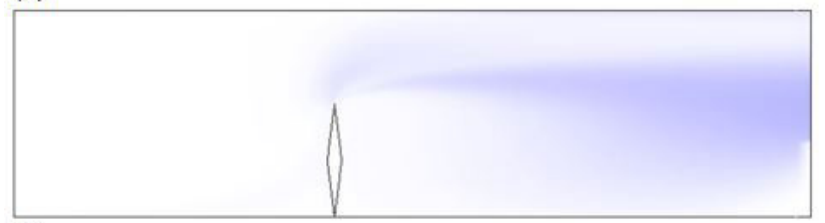

(b)

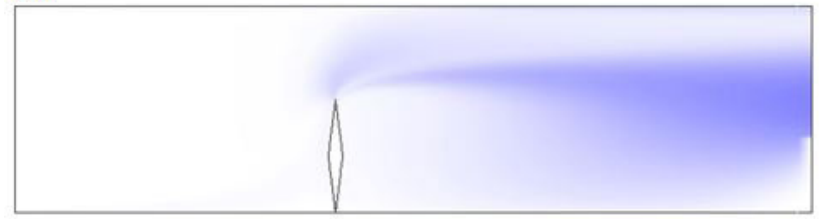

(c)

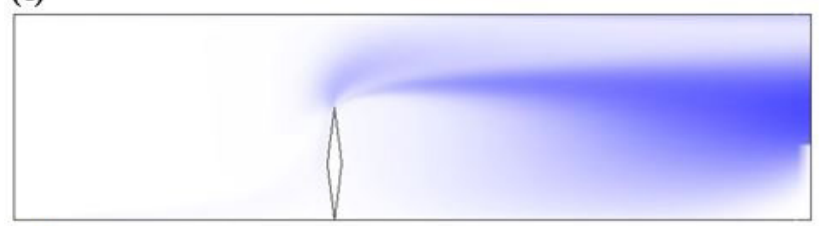

(d)

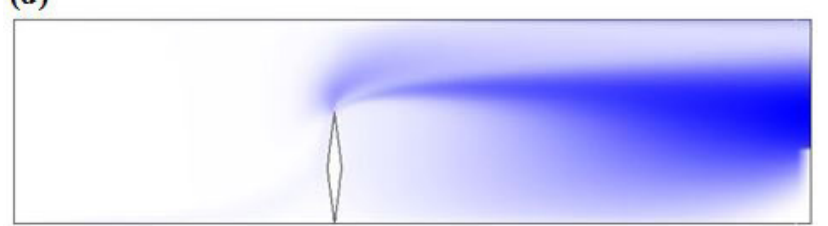

(e)

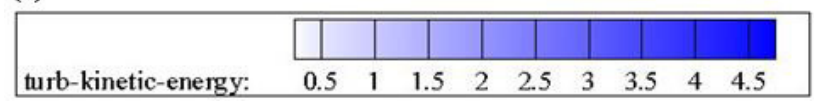

Fig. 9 Variation of turbulent kinetic energy with Re number:

(a) $\operatorname{Re}=12,000$, (b) $\operatorname{Re}=17,000$, (c) $\operatorname{Re}=22,000$, (d) $\operatorname{Re}=27,000$, and (e) $\operatorname{Re}=32,000$.

\subsection{Turbulent viscosity}

The contour plots of turbulent viscosity fields obtained under turbulent flow regime for the case of a channel with a lower wall-attached diamond-shaped baffle with various values of Reynolds number, i.e., $\mathrm{Re}=12,000$, $17,000,22,000,27,000$ and 32,000, are presented in Fig. 11 (a) to (e), respectively. The plots show the largest $T I$ value in the region downstream of the diamond baffle corresponding to the zone of vortex, and the smallest value in the regions around the left face of this same obstacle for all Reynolds numbers simulated. The TI augments with the augmentation of flow Reynolds number and thus, the $\mathrm{Re}=32,000$ provides maximum $T I$ values.

\subsection{Temperature field}

The thermal field, represented by the temperature contours, is shown in Fig. 12 (a)-(e) for five different values

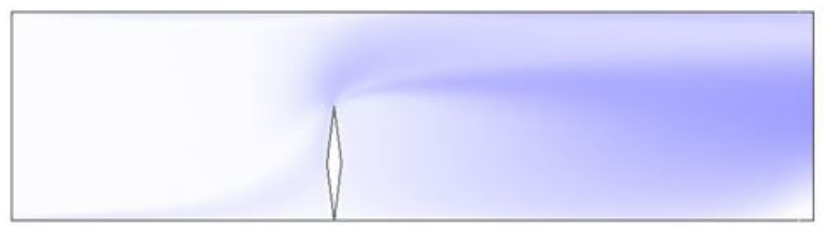

(a)

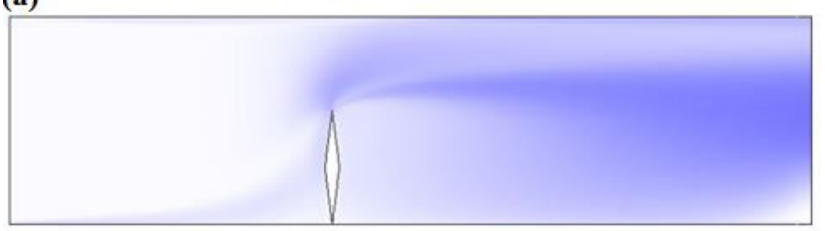

(b)

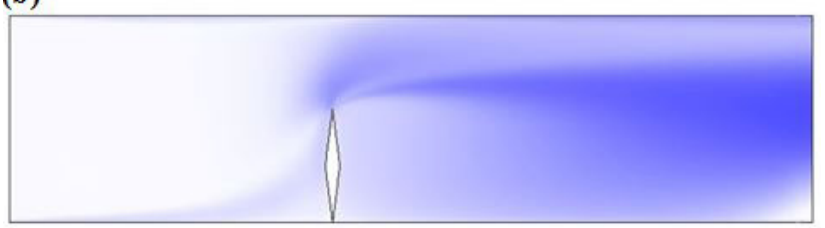

(c)

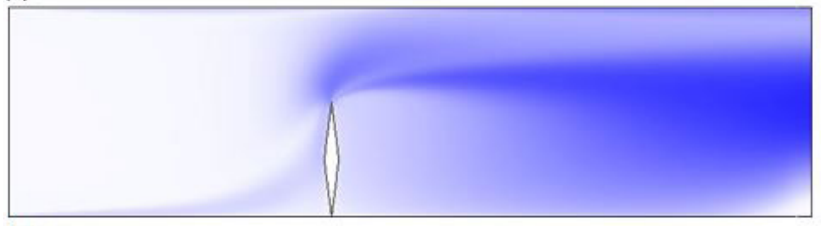

(d)

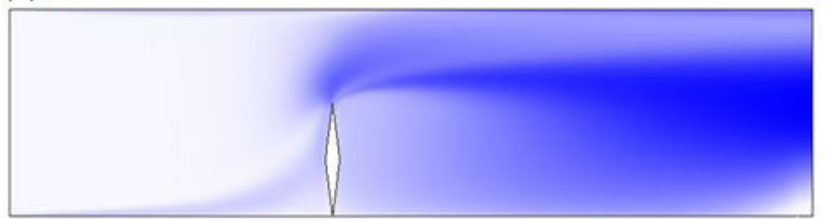

(e)

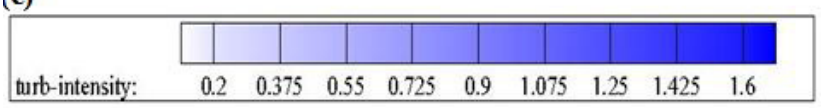

Fig. 10 Variation of $T I$ with $\operatorname{Re}$ (a) $\operatorname{Re}=12,000$, (b) $\operatorname{Re}=17,000$,

(c) $\operatorname{Re}=22,000$, (d) $\operatorname{Re}=27,000$, and (e) $\operatorname{Re}=32,000$.

$T I$ values in $\%(\times 100)$. 


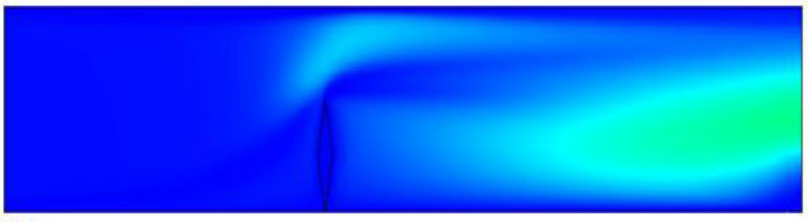

(a)

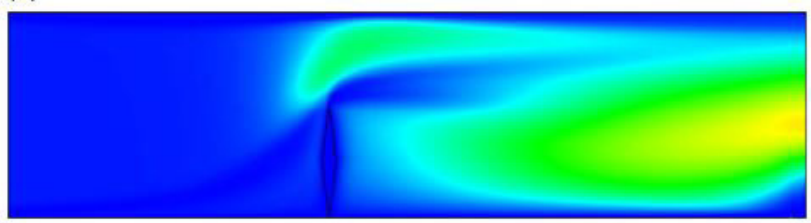

(b)

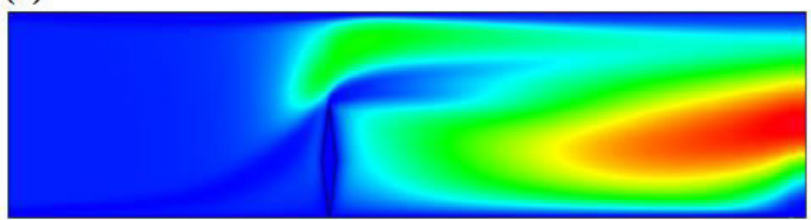

(c)

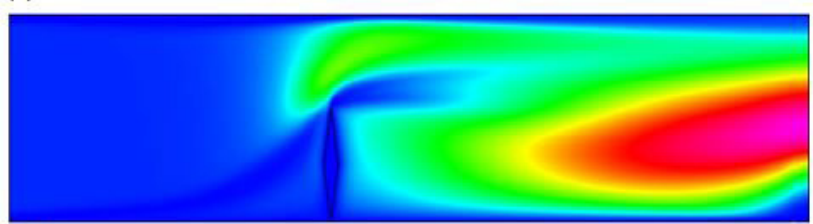

(d)

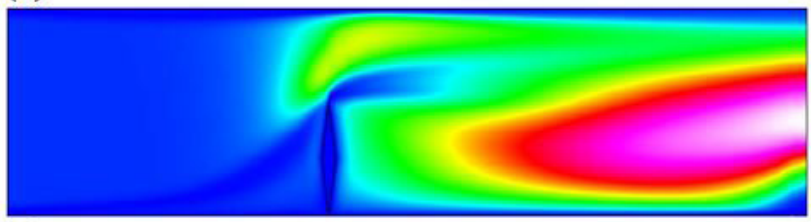

(e)

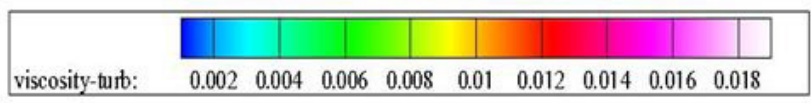

Fig. 11 Variation of turbulent viscosity with Re number:

(a) $\operatorname{Re}=12,000$, (b) $\operatorname{Re}=17,000$, (c) $\operatorname{Re}=22,000$, (d) $\operatorname{Re}=27,000$, and (e) $\operatorname{Re}=32,000$.

of Reynolds number, $\operatorname{Re}=12,000,17,000,22,000,27,000$, and 32,000, respectively. The field shown indicates a temperature drop in the regions situated between the end of diamond baffle and the upper wall of the channel, with an acceleration process that begins just after this same obstacle. Moreover, the temperature field shows that the air temperature in the recycling zone, downstream of the diamond baffle, is slightly higher than that obtained in the same region, but without any diamond baffles.

\subsection{Normalized average Nusselt number}

The variation of the normalized average Nusselt number $\left(\mathrm{Nu} / \mathrm{Nu}_{0}\right)$ with the Reynolds number range $(12,000-$ 32,000) is plotted in Fig. 13 for the situation under investigation. It is obvious that increasing the flow rate

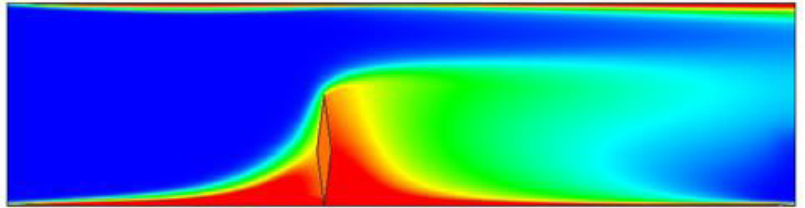

(a)

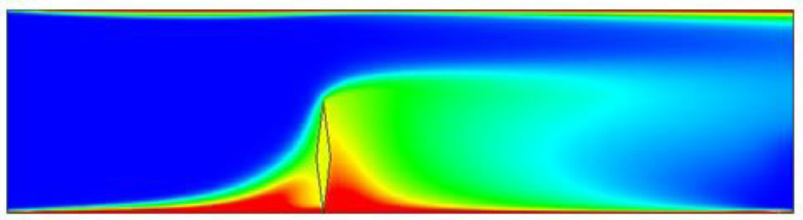

(b)

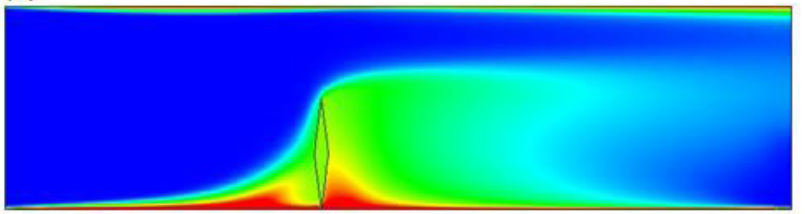

(c)

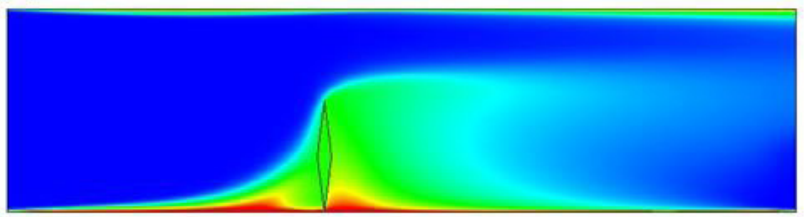

(d)

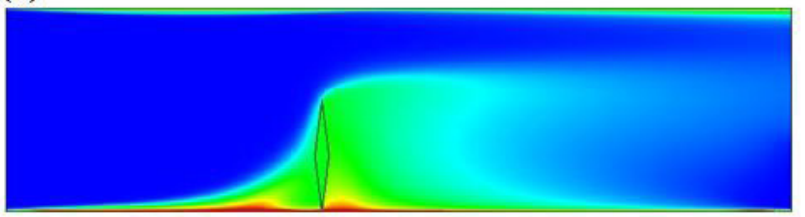

(e)

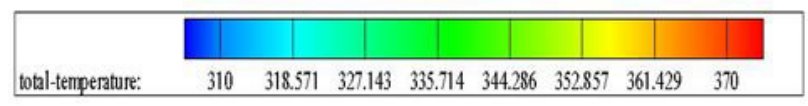

Fig. 12 Variation of temperature with Re number: (a) $R e=12,000$, (b) $\operatorname{Re}=17,000$, (c) $\operatorname{Re}=22,000$, (d) $\operatorname{Re}=27,000$, and (e) $\operatorname{Re}=32,000$.

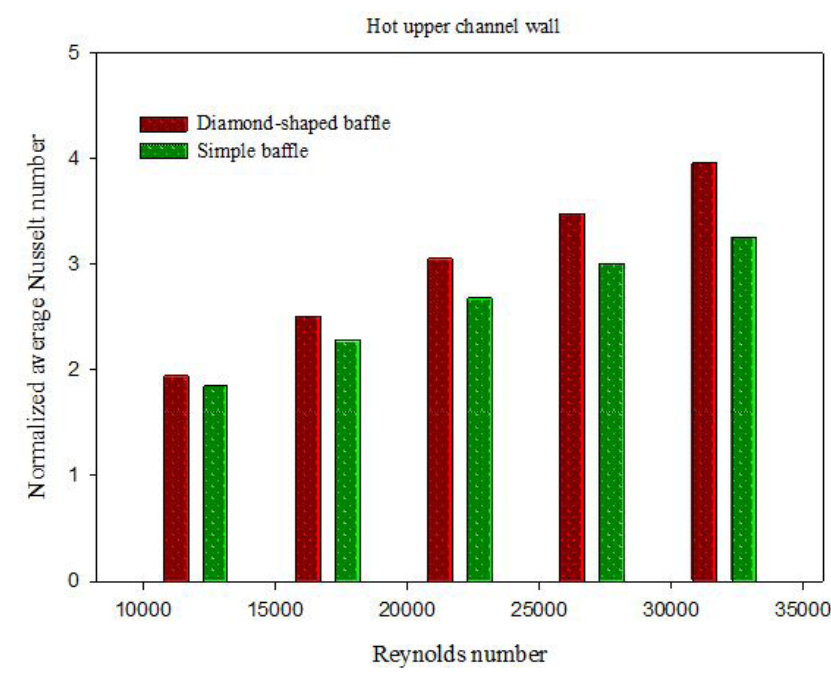

Fig. 13 Variation of normalized average Nusselt number with Re number. 
significantly raises the heat transfer rate due to the rise in the flow velocity in both of course, for high Reynolds numbers, temperatures drop significantly, as shown in Fig. 12. Therefore, there is an inverse proportionality between the increase in the Reynolds number and the temperature of the fluid, in each cross-section of the channel. As a consequence, the Nusselt number value rises as well. The maximum $\mathrm{Nu} / \mathrm{Nu}_{0}$ is obtained for $\mathrm{Re}=32,000$ while the lowest one is for $\mathrm{Re}=12,000$. The increases in $\mathrm{Nu} / \mathrm{Nu}_{0}$ values for using $\operatorname{Re}=12,000,17,000,22,000,27,000$, and 32,000, respectively, are about $194.423 \%, 250.784 \%, 305.351 \%$, $348.080 \%$, and $396.267 \%$ over the smooth rectangular air channel with no diamond baffle.

The diamond geometry provides higher $\mathrm{Nu} / \mathrm{Nu}_{0}$ rates than the simple geometry. The diamond-shaped baffle provides higher $\mathrm{Nu} / \mathrm{Nu}_{0}$ rate than the simple baffle around $5.046 \%, 8.943 \%, 12.241 \%, 13.625 \%$, and $17.794 \%$ for $\operatorname{Re}=12,000,17,000,22,000,27,000$, and 32,000 , respectively.

\subsection{Normalized friction factor}

The effect of the change in the flow Reynolds number on the profiles of the normalized friction factor $\left(f / f_{0}\right)$, along the hot upper wall, is shown in Fig. 14. The number of Reynolds has an impact on the average rate of friction; a correlation exists between the two variables. Indeed, increasing the Reynolds number results in a substantial growth in the fluid velocity (Fig. 6); the losses due to skin friction are also very significant, Fig. 14. The highest friction loss is detected at the highest Reynolds number $(\operatorname{Re}=32,000)$ while the lowest value of Reynolds number $(\mathrm{Re}=12,000)$ performs the lowest values.

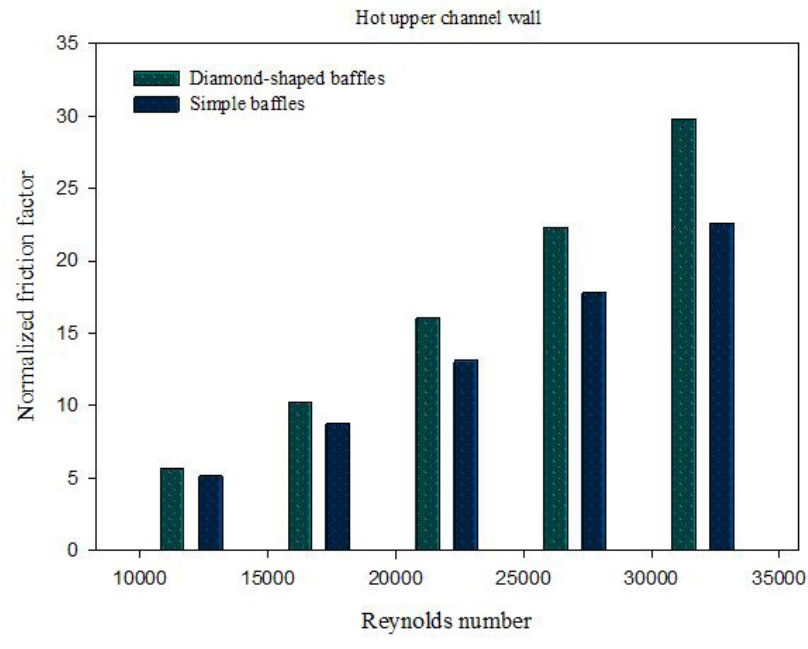

Fig. 14 Variation of normalized friction factor with Re number.
The diamond-shaped baffle provides higher $f / f_{0}$ than the simple baffle. The friction factor is around $5.683-29.820$ and 5.140 - 22.586 times above the smooth rectangular channel for the diamond and simple baffles, respectively.

\subsection{Thermal enhancement factor}

Fig. 15 presents the variations of the thermal enhancement factor $(T E F)$ with the flow Reynolds number for both the cases of simple and modern baffles. The thermal aerodynamic performance for air flowing in the simple or diamond baffled duct with larger Reynolds number is found to be higher than that with smaller flow rate. The $T E F$ value augment with the augmentation of Reynolds number (Re) and thus, the Re provides maximum thermal enhancement. The maximum TEF is around 1.292 at the highest Reynolds number for the case under study. This value decreases by $9.900 \%$ in a comparison with the simple baffle at the same upper Reynolds number.

\section{Conclusion}

This is a computational fluid dynamic analysis of air over a diamond-shaped baffle mounted on the hot upper surface of the lower wall of a rectangular cross section channel using a CFD technique. The Reynolds number was varied from 12,000 to 32,000 . The best configuration for using the baffle is found for the diamond geometry at upper Reynolds number values. Future work will involve more complex geometries and using nanofluids to assess the optimum conditions for heat transfer enhancements.

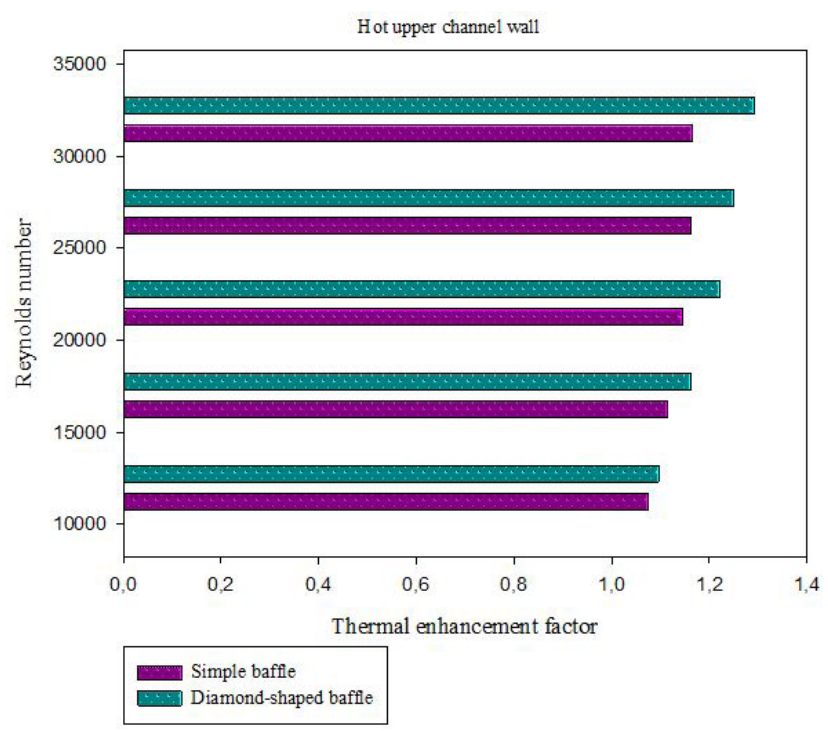

Fig. 15 Variation of $T E F$ with Re number. 


\section{References}

[1] Kelkar, K. M., Patankar, S. V. "Numerical Prediction of Flow and Heat Transfer in a Parallel Pplate Channel With Staggered Fins", Journal of Heat Transfer, 109(1), pp. 25-30, 1987.

https://oi.org/10.1115/1.3248058

[2] Habib, M. A., Mobarak, A. M., Sallak, M. A., Abdel Hadi, E. A., Affify, R. I. "Experimental Investigation of Heat Transfer and Flow Over Baffles of Different Heights", Journal of Heat Transfer, 116(2), pp. 363-368, 1994. https://doi.org/10.1115/1.2911408

[3] Hwang, R. R., Chow, Y. C., Peng, Y. F. "Numerical Study of Turbulent Flow over Two-dimensional Surface-Mounted Ribs in a Channel", International Journal for Numerical Methods in Fluids, 37(4), pp. 767-785, 1999.

https://doi.org/10.1002/(SICI)1097-0363(19991030)31:4<767::AIDFLD902>3.0.CO;2-A

[4] Karwa, R., Maheshwari, B. K., Karwa, N. "Experimental study of heat transfer enhancement in an asymmetrically heated rectangular duct with perforated baffles", International Communications in Heat and Mass Transfer, 32(1-2), pp. 275-284, 2005.

https://doi.org/10.1016/j.icheatmasstransfer.2004.10.002

[5] Singh, S., Chander, S., Saini, J. S. "Heat transfer and friction factor correlations of solar air heater ducts artificially roughened with discrete V-down ribs", Energy, 36(8), pp. 5053-5064, 2011. https://doi.org/10.1016/j.energy.2011.05.052

[6] Tamna, S., Skullong, S., Thianpong, C., Promvonge, P. "Heat transfer behaviors in a solar air heater channel with multiple V-baffle vortex generators", Solar Energy, 110, pp. 720-735, 2014. https://doi.org/10.1016/j.solener.2014.10.020

[7] Wen, J., Yang, H., Wang, S., Xue, Y., Tong, X. "Experimental investigation on performance comparison for shell-and-tube heat exchangers with different baffles", International Journal of Heat and Mass Transfer, 84, pp. 990-997, 2015.

https://doi.org/10.1016/j.ijheatmasstransfer.2014.12.071

[8] Zhao, H., Liu, Z., Zhang, C., Guan, N., Zhao, H. "Pressure drop and friction factor of a rectangular channel with staggered mini pin fins of different shapes", Experimental Thermal and Fluid Science, 71, pp. 57-69, 2016.

https://doi.org/10.1016/j.expthermflusci.2015.10.010

[9] Du, B.-C., He, Y.-L., Wang, K., Zhu, H.-H. "Convective heat transfer of molten salt in the shell-and-tube heat exchanger with segmental baffles", International Journal of Heat and Mass Transfer, 113, pp. 456-465, 2017.

https://doi.org/10.1016/j.ijheatmasstransfer.2017.05.075

[10] Skullong, S., Thianpong, C., Jayranaiwachira, N., Promvonge, P. "Experimental and numerical heat transfer investigation in turbulent square-duct flow through oblique horseshoe baffles", Chemical Engineering and Processing: Process Intensification, 99, pp. 58-71, 2016. https://doi.org/10.1016/j.cep.2015.11.008

[11] Mellal, M., Benzeguir, R., Sahel, D., Ameur, H. "Hydro-thermal shell-side performance evaluation of a shell and tube heat exchanger under different baffle arrangement and orientation", International Journal of Thermal Sciences, 121, pp. 138-149, 2017. https://doi.org/10.1016/j.ijthermalsci.2017.07.011
[12] Mokhtari, M., Gerdroodbary, M. B., Yeganeh, R., Fallah, K. "Numerical study of mixed convection heat transfer of various fin arrangements in a horizontal channel", Engineering Science and Technology, an International Journal, 20(3), pp. 1106-1114, 2017. https://doi.org/10.1016/j.jestch.2016.12.007

[13] Amraoui, M. A., Aliane, K. "Three-dimensional Analysis of Air Flow in a Flat Plate Solar Collector", Periodica Polytechnica Mechanical Engineering, 62(2), pp. 126-135, 2018. https://doi.org/10.3311/PPme.11255

[14] Rashidi, S., Eskandarian, M., Mahian, O., Poncet, S. "Combination of nanofluid and inserts for heat transfer enhancement", Journal of Thermal Analysis and Calorimetry, 135(1), pp. 437-460, 2019. https://doi.org/10.1007/s10973-018-7070-9

[15] Selimefendigil, F., Oztop, H. F., Chamkha, A. J. "MHD mixed convection in a nanofluid filled vertical lid-driven cavity having a flexible fin attached to its upper wall", Journal of Thermal Analysis and Calorimetry, 135(1), pp. 325-340, 2019. https://doi.org/10.1007/s10973-018-7036-y

[16] Akbarzadeh, M., Rashidi, S., Karimi, N., Omar, N. "First and second laws of thermodynamics analysis of nanofluid flow inside a heat exchanger duct with wavy walls and a porous insert", Journal of Thermal Analysis and Calorimetry, 135(1), pp. 177-194, 2019. https://doi.org/10.1007/s10973-018-7044-y

[17] Heydari, A., Akbari, O. A., Safaei, M. R., Derakhshani, M., Alrashed, A. A. A. A., Mashayekhi, R., Shabani, G. A. S., Zarringhalam, M., Nguyen, T. K. "The effect of attack angle of triangular ribs on heat transfer of nanofluids in a microchannel", Journal of Thermal Analysis and Calorimetry, 131(3), pp. 2893-2912, 2018. https://doi.org/10.1007/s10973-017-6746-x

[18] Khoshvaght-Aliabadi, M., Ariana, H., Khaligh, S. F., Salami, M. "Effects of delta winglets on performance of wavy plate-fin in PFHEs", Journal of Thermal Analysis and Calorimetry, 131(2), pp. $1625-1640,2018$. https://doi.org/10.1007/s10973-017-6527-6

[19] Menni, Y., Azzi, A. "Numerical Analysis of Thermal and Aerodynamic Fields in a Channel with Cascaded Baffles", Periodica Polytechnica Mechanical Engineering, 62(1), pp. 16-25, 2018. https://doi.org/10.3311/PPme.10613

[20] Menni, Y., Azzi, A., Chamkha, A. J. "Aerodynamics and Heat Transfer over Solid-Deflectors in Transverse, Staggered, CorrugatedUpstream and Corrugated-Downstream Patterns", Periodica Polytechnica Mechanical Engineering, 62(3), pp. 209-217, 2018. https://doi.org/10.3311/PPme.11972

[21] Menni, Y., Azzi, A., Chamkha, A. J., Harmand, S. "Effect of wall-mounted V-baffle position in a turbulent flow through a channel: Analysis of best configuration for optimal heat transfer", International Journal of Numerical Methods for Heat \& Fluid Flow, 2018. https://doi.org/10.1108/HFF-06-2018-0270

[22] Menni, Y., Azzi, A., Chamkha, A. "Modeling and analysis of solar air channels with attachments of different shapes", International Journal of Numerical Methods for Heat \& Fluid Flow, 2018. https://doi.org/10.1108/HFF-08-2018-0435 
[23] Menni, Y., Azzi, A., Chamkha, A. J. "Enhancement of convective heat transfer in smooth air channels with wall-mounted obstacles in the flow path: A review", Journal of Thermal Analysis and Calorimetry, 135(4), pp. 1951-1976, 2019. https://doi.org/10.1007/s10973-018-7268-x

[24] Fodor, A. "Calculation of the temperature of boundary layer beside wall with time-dependent heat transfer coefficient", Periodica Polytechnica Mechanical Engineering, 54(1), pp. 15-20, 2010. https://doi.org/10.3311/pp.me.2010-1.03

[25] Rábai, G., Vad, J. "Aerodynamic study on straight, arc-swept and twisted stationary linear cascade blades", Periodica Polytechnica Mechanical Engineering, 53(1), pp. 33-40, 2009. https://doi.org/10.3311/pp.me.2009-1.05

[26] Hegedűs, F., Rákos, R., Kullmann, L. "Experimental and numerical study on cavitating vortex shedding behind a square cylinder", Periodica Polytechnica Mechanical Engineering, 53(2), pp. 55-60, 2009.

https://doi.org/10.3311/pp.me.2009-2.01

[27] Füle, P., Hernádi, Z. "Investigation of turbulent channel flow using local mesh refinement", Periodica Polytechnica Mechanical Engineering, 58(1), pp. 7-13, 2014. https://doi.org/10.3311/PPme.7182

[28] Goda, R., Bánhidi, L. "Investigation of average air velocity and turbulence intensity in a slot ventilated space", Periodica Polytechnica Mechanical Engineering, 58(2), pp. 77-81, 2014. https://doi.org/10.3311/PPme.7264

[29] Bidar, B., Shahraki, F., Kalhori D. M. "3D Numerical Modelling of Convective Heat Transfer through Two-sided Vertical Channel Symmetrically Filled with Metal Foams", Periodica Polytechnica Mechanical Engineering, 60(4), pp. 193-202, 2016. https://doi.org/10.3311/PPme.8511

[30] Fenyvesi, B., Horváth, C. "Investigation on the Non-constant Behavior of a Vortex Flow Meter with Narrow Gauge Pipe via Conducting Measurements and Numerical Simulations", Periodica Polytechnica Mechanical Engineering, 61(3), pp. 247-254, 2017. https://doi.org/10.3311/PPme.10816

[31] Noghrehabadi, A., Behseresht, A., Ghalambaz, M., Behseresht, J. "Natural-Convection Flow of Nanofluids Over Vertical Cone Embedded in Non-Darcy Porous Media", Journal of Thermophysics and Heat Transfer, 27(2), pp. 334-341, 2013.

https://doi.org/10.2514/1.T3965
[32] Noghrehabadi, A., Pourrajab, R., Ghalambaz, M. "Effect of partial slip boundary condition on the flow and heat transfer of nanofluids past stretching sheet prescribed constant wall temperature", International Journal of Thermal Sciences, 54, pp. 253-261, 2012. https://doi.org/10.1016/j.ijthermalsci.2011.11.017

[33] Noghrehabadi, A., Pourrajab, R., Ghalambaz, M. "Flow and heat transfer of nanofluids over stretching sheet taking into account partial slip and thermal convective boundary conditions", Heat and Mass Transfer, 49(9), pp. 1357-1366, 2013. https://doi.org/10.1007/s00231-013-1179-y

[34] Demartini, L. C., Vielmo, H. A., Möller, S. V. "Numeric and experimental analysis of the turbulent flow through a channel with baffle plates", Journal of the Brazilian Society of Mechanical Sciences and Engineering, 26(2), pp. 153-159, 2004. https://doi.org/10.1590/S1678-58782004000200006

[35] Nasiruddin, Kamran Siddiqui, M. K. "Heat transfer augmentation in a heat exchanger tube using a baffle", International Journal of Heat and Fluid Flow, 28(2), pp. 318-328, 2007. https://doi.org/10.1016/j.ijheatfluidflow.2006.03.020

[36] Launder, B. E., Spalding, D. B. "The numerical computation of turbulent flow", Computer Methods in Applied Mechanics and Engineering, 3(2), pp. 269-289, 1974. http://doi.org/10.1016/0045-7825(74)90029-2

[37] Dittus, F. W., Boelter, L. M. K. "Heat transfer in automobile radiators of tubular type", International Communications in Heat and Mass Transfer, 12(1), pp. 3-22, 1985. https://doi.org/10.1016/0735-1933(85)90003-X

[38] Petukhov, B. S. "Heat Transfer and Friction in Turbulent Pipe Flow with Variable Physical Properties", Advances in Heat Transfer, 6, pp. 503-564, 1970. https://doi.org/10.1016/S0065-2717(08)70153-9

[39] Patankar, S. V. "Numerical Heat Transfer and Fluid Flow", Hemisphere, New York, USA, 1980. 